\title{
A TRIAL OF COMPRESSION SCLEROTHERAPY IN ARMY PERSONNEL
}

\author{
Major I. K. BAKSHI, M.B., F.R.C.S.E., R.A.M.C. \\ Lieutenant-Colonel H. Q. HUTCHINGS, M.B., F.R.C.S.E., R.A.M.C. \\ British Military Hospital, Munster
}

SUMMARY: Some 1500 patients with varicose veins attend Army clinics yearly in British Army of the Rhine (B.A.O.R.). The treatment of these cases results in considerable loss of manpower to the Army. A trial of Fegan's injection treatment was carried out in an attempt to reduce this wastage of man hours.

Twenty-three male and thirty-seven female patients with varicose veins of sufficient severity to require surgery were submitted to compression sclerotherapy.

Good results were achieved in the female patients. However, the results in the soldier were unsatisfactory and the length of time off full duties uneconomical. These results are discussed.

\section{Introduction}

Five-hundred operations on varicose veins were carried out during the year 1968/ 1969 in B.A.O.R. The average time before returning to full duties was two weeks. When the soldier's wife is in hospital, the soldier is released from duty to look after his family. Therefore, the loss of man hours to the Army as a result of operative treatment for varicose veins is one thousand weeks per annum in B.A.O.R.

In an attempt to reduce this loss of man hours we used Fegan's injection technique in sixty patients who would otherwise have required surgery during the year 1969/1970.

\section{Method}

Our technique did not differ from that described by Fegan. A $\frac{1}{2}$ to $1 \mathrm{ml}$ of Sodium Tetradecyl Sulphate is injected into the emptied segment of the superficial vein at the site of an incompetent perforator. While the vein is kept empty of blood by finger pressure, a bandage is applied above and below the injection site. The finger pressure is released and a further turn of bandage applied. A bevelled sorbo rubber pad is placed exactly over the injection site and the bandaging of this segment is completed. If further injections are to be performed these are carried out in a similar manner. The rest of the limb is then bandaged in separate segments (feet, calves, knee and thigh). A full length two-way stretch elastic stocking is fitted over the now injected and bandaged leg and held in place with a suspender. This method of bandaging is essential to the success of the treatment and must be retained for six weeks.

\section{Results}

The total number of patients treated and the results obtained are shown in Tables I to III.

\section{Discussion}

Good results were attained by those who rigidly followed our instructions and retained the bandages for the full six weeks. 
Table I

Patients treated and results
Table II

Patients treated and results

\begin{tabular}{|c|c|c|c|c|c|c|}
\hline \multirow{2}{*}{\multicolumn{2}{|c|}{ Total treated }} & \multicolumn{2}{|c|}{ Results } & \multirow{2}{*}{ Total males treated } & \multicolumn{2}{|c|}{ Results } \\
\hline & & Satisfactory & Poor & & Satisfactory & Poor \\
\hline $\begin{array}{l}\text { Males } \\
\text { Females }\end{array}$ & $\begin{array}{c}23 \\
37\end{array}$ & $\begin{array}{l}12 \\
33\end{array}$ & $\begin{array}{r}11 \\
4\end{array}$ & $\begin{array}{l}\text { Senior N.C.O's } \\
\text { Junior soldiers }\end{array}$ & $\begin{array}{l}4 \\
8\end{array}$ & $\begin{array}{r}1 \\
10\end{array}$ \\
\hline
\end{tabular}

Table III

Patients treated and results

\begin{tabular}{l|c|c|c|c|c|c|c}
\hline \multirow{2}{*}{ Patients by marital status } & \multirow{2}{*}{$\begin{array}{c}\text { Senior } \\
\text { N.C.O's }\end{array}$} & \multicolumn{2}{|c|}{ Results } & \multicolumn{2}{|c}{ Junior } & \multicolumn{2}{|c}{ Results } \\
\cline { 3 - 7 } & Good & Poor & soldiers & Good & Poor \\
\hline $\begin{array}{l}\text { Married } \\
\text { Single }\end{array}$ & 5 & 4 & 1 & 4 & 2 & 2 \\
\hline
\end{tabular}

Table IV

Cost to the Army per patient

\begin{tabular}{c|c}
\hline \multicolumn{1}{c|}{ Operation } & Fegan's method \\
\hline$£ 15.00$ per day $(£ 105.00$ per week $)$ & Materials used- $£ 2.00$ per leg \\
\hline
\end{tabular}

Good results are assessed by the production of a short fibrous cord replacing the varicose superficial vein and the disappearance of secondary incompetence. Poor results are indicated by thrombosis of the vein. Although this frequently will cause initial improvement and may satisfy the patient, recanalisation occurs and with it recurrence of symptoms.

The best results were found in the female group who with a few exceptions faithfully followed our instructions. The results in the married senior N.C.O's were also good. However very poor results were obtained in unmarried junior soldiers.

The junior unmarried soldiers live in barracks. There, they are subjected to the ridicule and the embarrassing remarks of some of their more unenlightened and unsympathetic colleagues. They run the risk of becoming a figure of fun and a target for the jibes and jests of the local barrack room comedians.

They have difficulty in personal hygiene particularly if both legs have been treated.

It is most important in the post treatment phase while the bandages are in place that the patient should avoid any prolonged standing. Therefore, they are not able to take part in guards, parades, or anything which involves long periods of standing. They are barred from schemes as it would obviously be impossible to keep the bandages clean and in position. Thus they are not fit for full duties for at least 6 weeks. This fact alone would make this treatment uneconomical in the Army.

A high percentage of our patients experienced severe pain within the first fortyeight hours of injection. If the rationale of the treatment is not fully understood by the general practitioner, general duty medical officer and other medical attendants, the 
logical reaction is to loosen the bandages, thereby defeating the whole object of this method of treatment. To achieve continuity of treatment, where there is a constant movement of doctors and medical attendants due to postings, is extremely difficult.

Some patients found itching particularly difficult to bear. This was more marked during the summer months and at night time.

Many patients declined treatment during the summer preferring to wait for the colder weather. Those who elected to have the treatment during the hot spells found that this added considerably to their discomfort. We therefore consider that this treatment is unsuitable for the tropics. The senior married N.C.O's did not suffer from the problems which caused so many of the junior soldiers to discontinue treatment and so the results were good. The only drawback amongst this group being the length of time that they were unfit for full duties.

Poor results were obtained in four of the females treated. In two of these the bandages were changed for crepe in the first twenty-four hours by the patient's doctor, in an attempt to relieve the pain. One patient removed the bandages herself at two weeks as she said the itching was intolerable. The fourth removed her bandages on the third day as she thought they were unnecessary. All the patients received implicit instructions with regard to the necessity for wearing the bandages and a careful explanation of the reasons for this necessity.

\section{Cost}

The cost to the Army per patient is given in Table IV.

\section{Conclusion}

We consider that Fegan's treatment of varicose veins is unsatisfactory in the junior unmarried soldiers. It is uneconomical in man hours in the soldier be he married or single, senior or junior.

However we would recommend this method of treatment in the female as the results in this group are eminently satisfactory and compare very favourably with operative treatment. It is unnecessary for the husband to lose any time at work as his wife is fit to carry out her normal household tasks. This represents a considerable saving in man hours bearing in mind that 303 of the 500 operative cases in B.A.O.R. in 1968/ 1969 were female.

\section{REFERENCE}

FEGAN, W. G. (1963). Continuous compression technique of injecting varicose veins. Lancet ii 109, 1963. 